\title{
La estructura mística de la crítica al concepto de progreso en la filosofía de Walter Benjamin*
}

The mystical structure of Walter Benjamin's philosophical criticism

of the concept of progress

\section{FACUNDO BEY}

Escuela de Humanidades, Universidad Nacional de General San Martín, Argentina. Consejo Nacional de Investigaciones Científicas y Técnicas, Argentina.

Facultad de Ciencias Sociales, Universidad del Salvador, Argentina.

Instituto de Filosofía «Ezequiel de Olaso»-Centro de Investigaciones Filosóficas, Argentina Instituto de Investigaciones Gino Germani, Universidad de Buenos Aires, Argentina. facundo.bey@gmail.com.

El objetivo general de este artículo es interrogar el lugar de la crítica a la idea de progreso en la filosofia de Walter Benjamin, argumentando que las raíces de su pensamiento político podrían encontrarse en el misticismo cabalista. La intención principal es determinar, siguiendo a Benjamin, algunas de las principales características de la creencia en el progreso como problema y su relación con una determinada normatividad histórica. Este recorrido permitirá elucidar la relación que, según el autor, mantendría una comprensión procesualista y lineal de la historia con una actitud politico-intelectual apoyada en el conformismo y la indiferencia. Por último, se propone considerar la original interpretación sobre la temporalidad que aparece en una vertiente del misticismo judío, el cabalismo de Isaac Luria de Safed, actualizada en forma heterodoxa por Benjamin, que permitiría comprender desde un nuevo punto de vista, conforme a la argumentación presentada, el vínculo temporal que supone la idea de tradición y rememoración en el materialismo histórico benjaminiano.

La catástrofe es el progreso, el progreso es la catástrofe (Benjamin, 2009, p. 73).

\section{Progreso y catástrofe}

En las célebres tesis de Über den Begriff der Geschichte [Sobre el concepto de historia] [1939-1940] el progreso se presenta por medio de una imagen

* $\quad$ El autor agradece los aportes de dos evaluadores anónimos de Revista SAAP, a una versión previa de este artículo. 
de innegable fuerza dialéctica ampliamente conocida: la de una implacable tempestad que empuja al «ángel de la historia» hacia el futuro y lo distancia irreversiblemente de la gran catástrofe que queda tras de sí, quedando así anulada toda posibilidad de empatía caritativa con las ruinas que esconden sus alas; permaneciendo este ángel, a su modo, dentro de la catástrofe misma, sin poder trascenderla. ¿Pero a qué progreso se refiere allí Benjamin?

[...] un progreso de la humanidad misma (no sólo de sus destrezas y conocimientos). En segundo lugar, es un [progreso] sin término (correspondiente a una infinita perfectibilidad de la humanidad). En tercer lugar, se lo tenía por incesante (como uno que recorriese espontáneamente un curso recto o en forma de espiral) (Benjamin, 2009, p. 48).

Esta no es sino la caracterización realizada por el berlinés de la noción de progreso que animaba la teoría marxista socialdemócrata y reformista, basada en la confianza en el mejoramiento continuo, a nivel científico, técnico, económico y moral, de una humanidad irreversiblemente pujante, dispuesta sobre una noción lineal del tiempo, y en dirección a su emancipación. Pero las alarmas benjaminianas no se reducían a su crítica sobre la situación del «progresismo» como movimiento ni a sus conclusiones sobre el rumbo, ingenuo y trágico al mismo tiempo, de la conformista socialdemocracia alemana. En las bases del partido de Karl Kautsky y Eduard Bernstein, organización funcional a la democracia liberal en cuanto nueva instancia del capitalismo, Benjamin, ciertamente, descubría la presencia subyacente de una filosofía de la historia evolucionista, insuficiente para comprender la naturaleza de un fenómeno que consideraba en los tempranos años '20 como una excepcional anacronía meridional: el fascismo. Pero también eran objeto de la aguda y fragmentaria pluma benjaminiana los fundamentos del discurso del materialismo histórico «oficial» del Kommunistische Partei Deutschlands [Partido Comunista Alemán] que, aunque revolucionario, permanecía encerrado teórica y prácticamente en su matriz stalinista, economicista-realista, incapaz de atender, desde su sistematismo teórico determinista, la necesidad de conmover la imagen de la continuidad del tiempo histórico (Benjamin, 2009), confiada hiperbólicamente, en los hechos, desde el Kremlin en Moscú y desde la clandestinidad en Alemania, al así llamado «Pacto Ribbentrop-Mólotov».

La deriva dominante del materialismo histórico — progresista, positivista e historicista a un mismo tiempo-impulsa a Benjamin no sólo a ser un crítico del historicismo burgués en sus distintas variantes, encarnado clásicamente en las figuras de Leopold von Ranke y Wilhelm Dilthey, así como 
en el neokantismo de la época, preeminente en Marburgo y Heilderberg, sino un cuestionador acérrimo de la ortodoxia marxista. Es que para Benjamin el positivismo asediaba por igual a las dos tendencias más importantes del marxismo de su tiempo. En este sentido hay que comprender la densa carga polémica de su tenaz y distintiva crítica al historicismo y a su imagen de la historia, así como los puntos de partida que le opuso en su propia y particular concepción del materialismo histórico, para el cual «la representación de la historia universal está vinculada a la del progreso y a la de la cultura» (Benjamin, 2009: 60) ${ }^{1}$.

El otro elemento fundamental que terminaría separando para siempre a Benjamin de la tradición marxista que le había precedido fue el diálogo que estableció en sus escritos entre el materialismo histórico y el misticismo y el mesianismo judío. A este tema está dedicado el último apartado de este artículo.

Si para la imagen de la historia en la que abrevaba el historicismo positivista, era preciso apoderarse del pasado «tal como ha sido verdaderamente» $y$ comprenderlo incluso mejor que como el pasado se había comprendido a sí mismo, para el materialista benjaminiano la articulación histórica «significa apoderarse de un recuerdo tal como éste relampaguea en un instante de peligro» (Benjamin, 2009: 41). ¿Pero, a qué peligro concretamente se refiere Benjamin? La respuesta a este sugerente rodeo nos permitirá reconocer más adelante la estructura mística de la reapropiación que propone el autor.

«La verdadera imagen del pretérito pasa fugazmente» (Benjamin, 2009: 41), afirmó Benjamin. A ese instante de peligro en que el recuerdo transcurre huidizamente le asiste un salvador de carácter mesiánico: el materialista histórico. Ante la «acedía» del historicista se yergue su único posible vencedor. La naturaleza del peligro es tan clara como fugaz: que una imagen del pasado, una y otra vez, logre convertirse en «herramienta de la clase dominante» (Benjamin, 2009: 42), que en su paso precario el historiador no sólo sea incapaz de transformar el recuerdo en tradición de los oprimidos, sino que haga de él su negación en el presente.

Encender «la chispa de la esperanza» (Benjamin, 2009: 42) es la última experiencia posible de la redención y sólo puede ser lograda atendiendo al secreto índice por el cual el pasado es remitido a una tradición, dejando a salvo lo sido [Das Gewesene] y a sus eventuales destinatarios (Benjamin, 2009: 71). El materialista histórico, distanciado críticamente de la infamia conocida como patrimonio cultural, podría dar con una verdadera, es decir, revolucionaria, y vencedora representación de la «felicidad» si lograra ser capaz de conmover la «tristeza historicista» (Benjamin, 2005: 484) de la que, como afirma en su Das Passagen-Werk [Libro de los Pasajes] [1927-40], está teñida la empatía con los vencedores.

También el Convoluto Nro. 13, 1 del Libro de los pasajes (Benjamin, 2005, p. 481). 
La experiencia de la redención que propone Benajmin se hace presente toda vez que se hace efectiva una victoria sobre el conformismo: «la redención es el limes del progreso» (Benjamin, 2009: 62). El conformismo historicista ejerce su violencia poniendo en peligro una tradición, la de la clase oprimida, y viciando su proceso de transmisión. Ese momento de peligro es el que solicita la redención de un Mesías y reclama la victoria sobre las figuras del Anticristo, a las que proponemos entender aquí como los conformismos de cada época. Entonces, es posible decir que es el conformismo quien «no ha dejado de vencer» en todo momento y que de esa manera cobra sentido que la tradición sea para Benjamin un campo de disputa permanente entre fuerzas materiales y espirituales. El historiador no sólo está en condiciones de apoderarse de la tradición de los oprimidos, sino de fundarla (Benjamin, 2009: 76) pero para eso no puede dejar de entender a la historia "como una constelación de peligros» (Benjamin, 2005: 472).

El progreso como problema, es también el desafío que plantea el Anticristo al historiador, esto es, evadir los encantos de una lengua seductora: la lengua del progreso y de su normatividad histórica, ya que para Benjamin, al decir de Elizabeth Collingwood-Selby

[...] La lengua es el lugar de la experiencia — no el medio a través del cual ésta se comunica-, el lugar del deseo y la rememoración. No hay experiencia fuera de la lengua. No existen los hechos consumados en el orden de la experiencia, lo que hay es un presente que tiene lugar como cita de un pasado pendiente; ese lugar es la lengua: lugar de manifestación del ser espiritual que en ella se comunica, no instrumento a través del cual se dice lo acabado (Collingwood-Selby, 1997: 127)².

La lengua del progreso es para el berlinés la de la historia universal: «La historia universal, en el sentido de hoy, sigue siendo sólo una suerte de esperanto (le da expresión a la esperanza de la especie humana del modo en que lo hace el nombre de aquella lengua universal)»(Benjamin, 2009, p. 62). Cuando Benjamin sostiene que los muertos no estarán nunca a salvo del enemigo, no se refiere a que el enemigo sea efectivamente invencible, algo que a primera vista parecería reducir al Mesías a una mera barrera katechonica cuya fuerza histórica se expresaría en su capacidad de demorar la aparición del Anticristo, sino que la normatividad histórica dominante impide, por definición, comprender la excepcionalidad permanente que implica la disputa al conformis-

A propósito, debe tenerse en cuenta que para Benjamin las visiones decadentistas de la historia se encuentran en la misma temporalidad que aquellas consideradas progresistas: progreso y decadencia son dos aspectos de la misma normatividad (Benjamin, 2005, p. 463). 
mo al tiempo que nos insensibiliza para escuchar la frágil reclamación de un pasado vencido. La máscara del asombro ante el aspecto regresivo de una catástrofe humana como la del genocidio, nos imposibilitaría ver en el espejo de la historia el propio rostro de la barbarie en la civilización. Con otras palabras, conformarse con la derrota definitiva del conformismo nos plantea un círculo sin salida que nos guía a una marcha abisal. La epigónica creencia moderna e ilustrada en el progreso defiende esta victoria sobre el conformismo no como una frágil posibilidad humana latente, sino como su más orgulloso pasado logro histórico, genuino, inédito y celebrable.

Como anticipáramos, las reflexiones sobre el problema del progreso en Sobre el concepto de historia permiten a Benjamin poner en cuestión al «progresismo» de la experiencia socialdemócrata en Alemania. El autor adjudica a la teoría y práctica socialdemócrata un concepto dogmático de progreso que se hacía efectivo tanto en sus tácticas políticas como en sus representaciones económicas y de cuyas consecuencias no nos ocuparemos pormenorizadamente (no nos equivocaríamos aquí si también incluyéramos nuevamente al marxismo economicista y a la realpolitik moscovita del comunismo «oficial»). Sin embargo, cada uno de los supuestos aislados de esta crítica nos dice demasiado poco si no logramos ver lo que tienen de común para Benjamin: la representación del progreso humano como indisociable de «la representación de su marcha recorriendo un tiempo homogéneo y vacío» (Benjamin, 2009: 48). Sólo a partir de la puesta en común de sus predicados accedemos a componer y conmover la imagen de esta marcha, imagen que debería sentar las bases para «la crítica a la representación del progreso absoluto» (Benjamin, 2009: 48), resultando una mónada que nos pudiera poner en relación desde el ahora con lo sido (Benjamin, 2005: 464).

El tiempo homogéneo y vacío, dimensión interminable y de lo sin término, receptáculo de la masa aditiva de hechos del historicismo positivista, es contrapuesto por Benjamin a la detención «irruptiva» que llama Jetztzeit [tiempo-ahora]. Desde la conciencia del presente que implica este «tiempo histórico» es posible «poner en obra la experiencia con la historia» (Benjamin, 2009: 40, 50), construir la historia, hacer saltar su continuidad en un instante de acción inscripto en los márgenes de una temporalidad mesiánica ${ }^{3}$. El lugar del dogma progresista y su representación de la marcha que allí ocurre resulta una negación de la caducidad tanto como lo es la imagen

Para el historiador el presente se convierte en objeto intencional de una retro-profecía: su mirada de vidente debe escapar del propio tiempo y sumirse en el pretérito para comprender mejor su situación, no con la mirada empática del historicista, sino con la mirada redentora del revolucionario que ve interrumpida la pasiva narración de nexos causales por una tradición de fatalidades pasadas. Construir la historia, para el historiador materialista, no supone reconstruirla empáticamente, sino más bien antes, destruirla (Benjamin, 2005; Benjamin, 2009). 
eterna del pasado postulada por el historicismo, el desgastado y narcótico «érase una vez» (Benjamin, 2005: 465; Benjamin, 2009: 50). Pero si se lograra desmontar la representación de la historia como progresión sería posible poner en jaque los tres pilares del historicismo: la idea de la historia universal, la idea de que a la historia se la puede narrar, y la empatía con el vencedor. A este mencionado sustituto Benjamin le propina un shock que permitiría interrumpir fugazmente esa marcha o, al menos, ponerla en suspenso.

\section{La Gran Marcha (hacia adelante)}

En este breve apartado realizaré una breve digresión basada en una reconocida obra de la literatura contemporánea que relaciona esta imagen de la marcha del progreso con el concepto de kitsch y con la política, con el objetivo de hacer aún más claras las consideraciones de Benjamin ${ }^{4}$.

Milan Kundera, escritor nacido en Brno, dos veces expulsado del Partido Comunista Checoslovaco, prohibido en su país por las autoridades soviéticas y exiliado desde 1975 en Francia, ofreció en su novela La insoportable levedad del ser (1984) una serie de reflexiones que creemos podrían ser útiles para echar luz sobre lo anterior.

Ambientada en la tumultuosa Praga de 1968, en su novela Kundera define al kitsch como la negación ontológica de todo lo que en la existencia humana es inaceptable, es decir, todo aquello que se encontraba en buena parte presupuesto en el objetivo «simplemente bueno» que habría, hubiera debido o estaría aún en condiciones de alcanzar Occidente por mor del voluntarismo. Sobre el kitsch se edifica, con todo el sentimentalismo y conformismo posible, el hermanamiento de los hombres del mundo, sin importar en realidad si pertenecen a la Praga comunista o a los occidentales Estados Unidos (tal como lo testimonia Sabina en su encuentro con su amigo el senador).

El fundamento del kitsch es lo que llama un «acuerdo categórico con el ser», de claras consecuencias estéticas y éticas. Se trataría de una fe quasi neoplatónica que entiende que el mundo fue creado en modo totalmente correcto y en cuyo dominio impera la dictadura del corazón (Kundera, 2011: 260-262).

La definición de Kundera se acerca indudablemente, desde este punto de vista, a las reflexiones de Theodor Adorno en su Ästhetische Theorie [Teo-

En lo que respecta a la obra de arte, Benjamin afirma en el Libro de los Pasajes que el kitsch es «arte con un carácter de uso, absoluto y momentáneo» capaz de acercarse a las masas y sus exigencias, proporcionando un cálido «confort del corazón» (Benjamin, 2005: 401). Es posible que Benjamin rescate este acercamiento del cine, por caso, con las masas ya que parece imposible de lograr a través del ardor del odio que fuera necesario provocar en ellas una vez que las clases trabajadoras desaprendieran el odio y la voluntad del sacrificio en la escuela socialdemócrata (Benjamin, 2009: 47). 
ría Estética] (1970). Allí el autor alemán sostiene que: «lo kitsch es (...) lo bello en tanto que feo, tabuizado en nombre de lo bello que fue en otros tiempos y a lo que contradice debido a la ausencia de su contrario», «belleza purificada», «basura sentimental» (Adorno, 2004: 94). La idea de la sustitución de lo bárbaro en lo civilizado se adaptaría, de este modo, perfectamente a esta noción del kitsch.

Como es evidente, Kundera no se refiere aquí exclusivamente al kitsch como una cualidad objetiva sino a comportamientos individuales y colectivos. El kitsch para Kundera no se agota en este «acuerdo categórico con el ser», en este festejo de la creación que incita a la sustitución (o superación) de cualquier aspecto negativo de la existencia humana, sino que obtiene múltiples modos de aparición dependiendo de la base sobre la que se pretenda sostener. En el caso del kitsch político, el ser que está en su base se constituye por «intuiciones, imágenes, palabras, arquetipos» (Kundera, 2011: 269) en los que se afirman los distintos movimientos políticos, cuya deriva totalitaria se expresa no sólo en la pesadumbre que entristece y apaga la ironía (la broma, zert) de quien se permite dudar, sino también en la necesidad de negar y eliminar con máxima seriedad, planificación y racionalización a lo inaceptable y a los inaceptables.

Según el autor checo, el kitsch político se habría inaugurado en la modernidad con el par izquierda-derecha, el cual parece ser entendido por el autor únicamente bajo los vectores del retorno o del progreso. La descripción de ambos kitsch y su distinción se pierde en el texto en la medida que el autor avanza hacia la caracterización de la idea que embriaga a Franz y que aquí queremos recuperar. Franz es descripto como un hombre de izquierdas, aunque poco importan las «teorías» que harían de él un izquierdista (dictadura del proletariado o democracia, rechazo a la sociedad de consumo o incremento de la producción, guillotina o suspensión de la pena de muerte), pues lo que lo haría tal sería «su capacidad de convertir cualquier teoría en parte del kitsch llamado Gran Marcha hacia delante» (Kundera, 2011: 269).

[...] La idea de la Gran Marcha, es el kitsch político que une a las personas de izquierda de todas las épocas y corrientes. La Gran Marcha es ese hermoso camino hacia delante, el camino hacia la fraternidad, la igualdad, la justicia, la felicidad y aún más allá, a través de todos los obstáculos, porque ha de haber obstáculos si la marcha debe ser una Gran Marcha (Kundera, 2011: 269).

Sin embargo, el siglo XX y sus catástrofes humanas —así como Franztuvieron la impresión de que la Gran Marcha había concluido su espiral en las fronteras del silencio: 
La Gran Marcha no es más que un pequeño podio en medio del planeta. Las masas que antes se apretujaban alrededor del podio hace tiempo ya que se han vuelto de espaldas, y la Gran Marcha continúa a solas y sin espectadores. (...) La Gran Marcha continúa, a pesar del desinterés del mundo, pero se vuelve nerviosa y febril. (...) es una marcha de gentes que da saltos, que tienen prisa y el escenario es cada vez menor, hasta que un día se convierta un mero punto sin dimensiones (Kundera, 2011: 279).

Es notable la afinidad entre este «hermoso sueño» en el que vive Franz con la representación, corpus de la crítica de Benjamin, de un indefinido progreso humano que transcurre en un «tiempo homogéneo y vacío» —en las teorías liberal-burguesas, socialdemócratas o stalinistas por igual- y en el que el kitsch representa la «suprema y última caricatura» histórica «del árbol totémico de los objetos» (Benjamin, 2005: 231).

Incluso, también la relación entre el kitsch y el sueño podría ser remarcada aquí desde otra acepción benjaminiana: su carácter onírico le restaura al kitsch progresista su sublime banalidad, pone en marcha la estetización mitopolítica del hombre europeo en el capitalismo (Benjamin, 2005: 396), y parece absorber bajo su máscara la «pobreza de experiencia» de la vigilia plena. La obligación del historiador materialista será pues despertar de este sueño que sueña la vigilia absoluta. Pero, este despertar no puede significar levantarse de un salto, gracias a la cálida y matinal luz racional del sol que entra por la ventana de la consciencia iluminándolo todo, sino un escandir el presente lapso de tiempo [Zeitraum] que no es sino un tiempo onírico [Zeit-traum] (Benjamin, 2005: 394). Despertar es pasar por los sueños, es un modo de recordar, «es el giro dialéctico, copernicano, de la rememoración» (Benjamin, 2005: 394), un acto combativo de origen y naturaleza colectiva (Benjamin, 2005: 232). Tal como reza en su glosa sobre el surrealismo de 1927, titulada Traumkitsch [Kitsch onírico], «el soñar participa de la historia» (Benjamin, 1993: p. 36),

¿Qué quedaría del kitsch progresista una vez que el silencio hubiera estrechado sus fronteras, zanjando un abismo? Continuaría, pero, en palabras de Kundera, como kitsch: a medio camino entre ser y olvido (2011, pp. 290).

El método histórico es un método filológico, que tiene en su base el libro de la vida. "Leer lo que nunca fue escrito», reza en Hofmannstahl. El lector en que ha de pensarse aqui es el verdadero historiador (Benjamin, 2009: 86). 


\section{La mística judía del cabalismo. Conmemoración y regreso.}

Michael Löwy en Redención y utopía (1997) y Walter Benjamin: Aviso de incendio (2003), caracterizó al pensamiento de Benjamin como una articulación de mesianismo y marxismo: «[...] Un pensamiento innovador, original, inclasificable, caracterizado por lo que él llama, en una carta a Scholem de mayo de 1926, la "paradójica reversibilidad recíproca» (Umschlagen) de lo político en lo religioso y viceversa» (Löwy: 2003: 42).

En Das Passagen-Werk, Benjamin afirmó «Mi pensamiento se relaciona con la teología como el papel secante con la tinta. Está empapado en ella. Pero, si pasara al papel secante, no quedaría nada de lo escrito» (Benjamin, 2005: 473). La cita que hemos escogido como epígrafe de este apartado, en la que se menciona al escritor Hugo von Hofmannstahl — con el que Benjamin mantenía fluida correspondencia- y al luriánico Libro de la vida (o Arbol de la vida, Etz Jaim) tiene como objetivo introducir lo que consideramos una alternativa para comprender las raíces místicas de la noción bejaminiana de redención y rememoración.

La hipótesis que aquí se propone es que el misticismo cabalista medieval podría haber proveído a Walter Benjamin un andamiaje teológico-político compatible con el desarrollo de una idea de práxis, capaz de componer un nuevo sentido para un mundo azotado por la desesperanza de la catástrofe totalitaria.

Por supuesto, es sabido que Benjamin tomó conocimiento del cabalismo a través de Gershom Scholem, con quien inició su amistad en 1915. Pero no es nuestro objetivo dar cuenta en profundidad de los contenidos e influencias que pudieran haberse dado entre ambos con relación al cabalismo, sino avanzar sobre la estructura de este pensamiento místico que podría proporcionar claves para la comprensión del papel del historiador revolucionario y de la tarea que implica la redención y su vínculo cooriginario con la restitución que comporta el concepto luriánico de tikkun o enmienda.

Para elaborar esta reconstrucción, primero debemos introducir brevemente el pensamiento místico desarrollado por el cabalista Isaac Luria de Safed [1534-1572], apodado honoríficamente el $a r^{5}$, es decir, el león. Luria nunca escribió, pero sus enseñanzas sobre la creación y la redención y su reinterpretación de la Kabbalah teórica y práctica, plasmadas en los textos que se conocen con el nombre de Kitvei Ha'Ari (Escritos del Ari), fueron llevadas al papel y legadas a la posteridad por parte de su principal discípulo, Jaim Vital.

La obra de Luria dentro de la tradición cabalista es central e implicó una importante ruptura: su vida estuvo dedicada a desarrollar una inter-

Existe controversia sobre qué significaría la palabra ari en cuanto acrónimo. 
pretación de la Kabbalah capaz de ser comprendida por todos los judíos. Luria, con este objetivo, incorporó a la tradición cabalista una nueva terminología y simbolismo. En su obra, se destacó su original análisis de la naturaleza del tzimztum o contracción divina y la naturaleza dual del desarrollo dialéctico del mundo por medio de la hitpashetut (egresión) y la histallekut (regresión) de las fuerzas divinas. Pero es fundamentalmente a su noción de tikkun a la que se le dará especial atención en este apartado para ampliar el sentido de la Eingedenken bejaminiana.

Efectivamente, fue Scholem el primero en introducir la noción de tikkun en la interpretación de Benjamin (1983), noción que, a pesar de que Benjamin nunca la utilice deliberadamente, Scholem sostuvo que le era conocida por medio de la lectura de la obra de Franz Joseph Molitor y de su propio artículo titulado Kabbalah (Scholem, 1983: 66-67; Benjamin, 1997: 239-240). La tesis de Scholem, sin embargo, no es aquí de nuestro interés, ya que va en otra dirección: para Scholem, Benjamin confunde al Mesías con el ángel de la historia al asignarle la tarea de despertar a los muertos y restablecer lo dañado (Scholem, 1983: 66-67).

Debemos, por otra parte, a Harold Bloom (1992) una relectura (o «mala lectura» [misreading] con sus palabras) de la obra de Isaac Luria en forma de una «teoría de la influencia», metodología hermenéutica la de Bloom, enfrentada a la transparencia del lenguaje y a la linealidad, que, vale decirlo, el mismo Benjamin había ya reconocido en 1927 en André Breton como fórmula del ««malentendido dialógico», es decir, de lo que está vivo en el diálogo. Pues «malentendido se llama el ritmo con el cual la única verdadera realidad se abre paso en la conversación» (Benjamin, 1993: 37).

Bloom parte del supuesto de que todas las teorías cabalísticas de la emanación (aquellas que entienden a los sephirot como emanaciones divinas a partir de las cuales se estructura la realidad) son teorías del lenguaje ya que su poder de significación se manifiesta como giros del lenguaje que sustituyen a Dios (en sus varios nombres) (Bloom: 1992: 25-26). Nos dice Bloom que la Kabbalah de Luria es considerada por Gershom Scholem un «mito del exilio» (Bloom: 1992: 24) y es esta imagen la que, a nuestro criterio, puede ofrecernos un nuevo sentido vinculado a algunas de las reflexiones que hemos reseñado de Walter Benjamin así como, en particular, su interpretación sobre el tikkun.

Kabbalah significa tradición en el sentido de recepción (Bloom: 1992: 15). El punto de partida del «mito del exilio» de Luria se encuentra en una situación suficientemente elocuente: el problema de los cabalistas de la España medieval para disponer de «[...] un nuevo impulso religioso, fresco y vital, en una época de disturbios, precaria y casi catastrófica, cuando se hereda una tradición religiosa tan rica ya y coherente que da poca cabida a nuevas revelaciones o incluso reflexiones» (Bloom: 1992: 33). Se podría tal 
vez reescribir para Benjamin el problema de los cabalistas en la siguiente pregunta: ¿Cómo es posible fundar una tradición subvirtiéndola para evitar así el conformismo ante lo consagrado en medio de una desazonada época de catástrofes? ¿Cómo podría pensarse esto último con relación al materialismo histórico en cuanto tradición?

La respuesta que dio Luria estuvo inscripta en el marco de un movimiento que buscó aplicar a las Escrituras y comentarios el sufrimiento histórico de las masas oprimidas del pueblo judío, otorgándole una experiencia de fe más inmediata que la que podía proporcionarle la tradición ortodoxa (Bloom: 1992: 34). Hasta Luria, la Kabbalah había entendido a la creación como un proceso «progresivo» que se movía en una sola dirección, sin grandes sobresaltos. Pero su planteo fue disruptivo: sostuvo que la creación era un proceso enfáticamente «regresivo», «en que el abismo puede separar a cualquier etapa de otra y en que la catástrofe es siempre un acontecimiento principal» (Bloom: 1992: 39). La regresión no tiene aquí un sentido lineal o unidireccional, sino que sólo puede comprenderse en los márgenes de la discontinuidad. La realidad, entonces, se estructuraría en un omnipresente triple ritmo de contracción, ruptura y enmienda: tzimtzum, sherivat hakelim, tikkun.

Este triple proceso de limitación divina, sustitución del significado del patrón original y representación restitutiva, no exime a la creación de la presencia del mal en la existencia ni la sustituye. Según el Zohar (el principal «libro» de la tradición cabalística), en el momento de la ruptura, parte de la luz divina liberada en la creación cayó hasta conformar las kelippot o fuerzas malignas. Pero en las kelippot (o cortezas del Árbol de la Vida que constituyen los sephirot) «hay chispas que pueden redimirse» (Bloom: 1992: 38) y respecto a esto último es que la postura de Luria se torna tan significativa. Por un lado, en su teología sólo era posible la creación a partir de una catástrofe (la catarsis divina) y, a su vez, el tikkun, en tanto operación restitutiva, es una obra puramente humana: actos de meditación «que exaltan y así liberan a las divinas chispas caídas de su prisión en los cascos de los kelippot»(Bloom: 1992: 41-43). De manera que el revestimiento místico de la tarea humana, a la vez que explica la existencia del mal, hace de la observancia y la oración el camino que allana, desde el sufrimiento presente del mundo, la venida del Mesías.

Lo anterior significa que la tikkun introduciría de manera eminente el papel de la acción humana dentro del proceso de redención. Ahora bien, según Bloom, la enmienda del tikkun no es una restitución en el sentido del movimiento que lleva a reponer lo original creado y destruido en la Shevirat. La Kabbalah entiende siempre al significado como algo lesivo y lo único reintegrable es el significado primordial de la Torah como enseñanza divina de la escritura y no como texto. Lo que hace al tikkun representación reparadora es un gesto de restitución y no una efectiva restitución absoluta de la 
creación. En última instancia, el tikkun es un recordatorio, una conmemoración, una Eingedenken que «funciona para hacernos recordar lo que nunca hubiéramos podido saber y que, con todo, necesitamos creer que hemos sabido» (Bloom: 1992: 85).

El modelo filológico de la creación que legó Luria toma su fuerza del «retorno». Pero aquí retorno no significa regreso a la perfección del origen, al Edén. El retorno como reparación sólo se alcanza en forma parcial y por manos humanas. Para lograr tal reparación es preciso atender al recuerdo de una catástrofe lejana (el exilio del pueblo hebreo en Egipto) que se hace eco de una catástrofe actual (el exilio de la España de la Inquisición) y cuyo puente permanece en secreto para quien no tiene esperanza en la redención y busca conocer el futuro por medio de vates. El lenguaje divino es el lugar de la experiencia que da sentido al sufrimiento histórico y a partir del cual es posible encender la chispa de la esperanza por medio de la rememoración.

\section{Conclusiones}

Con Isaac Luria de Safed aparece en la Kabbalah la formulación que pone en igualdad al futuro con el origen: tikkun, «la reintegración del todo original» que pone al presente, a su vez, cara a cara con la inminente llegada del Mesías y la restauración prístina. Walter Benjamin, por su parte, ofrece una variante interesante sobre la redención, aquí comentada sucintamente, y que no se contradice con la propuesta de Luria en la medida que la posibilidad de redención del materialista histórico es siempre parcial y frágil, mientras que su sentido total sólo cabe ubicarlo fuera de la historia: en el día del Juicio Final (Benjamin, 2009: 40, 69) .

El progreso, desde el punto de vista del judaísmo cabalista es inconcebible, pues «a los judíos les estaba vedado investigar el futuro»—como afirmó Benjamin - mientras que, por el contrario, la Torah y la oración «los instruyen en la remembranza» (Benjamin, 2009: 53). La restauración del tikkun es la de la práctica integral de la Torah y el mesianismo su posibilidad latente o secundaria. Tal como sostenía Benjamin, esta forma de concebir la vida impedía al judaísmo que el futuro se le presentara como un tiempo homogéneo y vacío, ya que «...en él cada segundo era la pequeña puerta por la que

Cabe recordar también el célebre Fragmento teológico-político: «Sólo el Mesías mismo consuma todo acontecer histórico, y en ese sentido: sólo y primeramente él libera, consuma, crea la relación de ese [acontecer] con lo mesiánico mismo. Por eso nada histórico puede pretender relacionarse de por sí con lo mesiánico. Por eso el Reino de Dios no es el telos de la dynamis histórica; no puede ser puesto como meta. Históricamente visto, no es meta, sino fin. Por eso el orden de lo profano no puede construirse sobre el pensamiento del Reino de Dios...» (Benjamin, 2009: 141). 
podía entrar el Mesías» (Benjamin, 2009: 53). La conmemoración, la remembranza o «pensar rememorante» [Eingedenken] (Benjamin, 2009: 48, 53), como modo de vida, puede poner a salvo al pasado en su fragilidad por medio de la interrupción del presente en cada retorno: esta tensión entre continuidad y discontinuidad es la de dos tradiciones tratando de adueñarse de la historia y sus representaciones: una que amenaza con igualar todo al suelo amparada en un recreado continuum de la historia y otra que, consciente de la discontinuidad histórica, sabe ver en cada situación política una chance revolucionaria para entrar en acción y luchar por el pasado oprimido (Benjamin, 2009: 50, 58, 65). La Eigendenken habilita teológicamente a la historia en la conversión del sufrimiento concluido en algo inconcluso (Benjamin, 2005: 473).

Por tanto, en el pensamiento benjaminiano la estructura del tikkun determina la regresión a la catástrofe como modalidad de la praxis. Esta última implica una enmienda siempre parcial de la apropiación material y simbólica de la historia que transcurre en el tiempo vacío y homogéneo del pensamiento progresista, revelando las chispas de esperanza ocultas en la dominación, incluso en la dominación más confortable y optimista. Esto conduce a una interpretación conceptual de la tradición de los oprimidos en términos de la Kabbalah. De tal modo, la tradición así entendida no es ni empatía con los vencedores ni con los vencidos sino el hilo que reúne -mediante el rememorar-a los oprimidos de todas las épocas en la acción revolucionaria.

El vínculo temporal que une el ahora y lo sido en el que acontece la práxis como enmienda restitutiva y crítica de la normatividad histórica progresiva, provee al materialismo histórico de su unidad monádica: cada segundo abre la puerta a la puesta en común del tiempo y del quehacer revolucionario. El eco de la catástrofe capitalista habilita míticamente una experiencia inmediata de la suspensión de los conformismos políticos y de su comprensión como constelación de peligros.

Por último, el modelo de tradición que funda el pensar rememorante benjaminiano resignifica la esperanza. Esta última ya no es entendida como confianza ciega en la marcha de un progreso indefinido, sino como una disposición práctica contra la violencia bárbara del olvido civilizado, como necesidad de «organizar el pesimismo» (Benjamin, 2009: 62). Esto significa «descubrir en el espacio de la acción política el [...] espacio de la imagen» (Benjamin, 2009: 62), escandir el tiempo para abrir una legibilidad de las imágenes dialécticas, una cognoscibilidad actualizada en y mediante una práxis que funde, como un relámpago fugaz, presente y pasado.

La alarma benjaminiana no busca despertar una consciencia táctica en términos de correlación de fuerzas: prepara al revolucionario para convertir la espera en acto, para hacer del momento preciso «el» ahora. 


\title{
Referencias bibliográficas
}

Adorno, Th. (2004). Teoría Estética. Madrid: Ediciones Akal.

Benjamin, W. (1993). Kitsch onírico. Glosa sobre el surrealismo. En Punto de Vista. Revista de Cultura, 47.

Benjamin, W. (2005). Libro de los pasajes. Madrid: Ediciones Akal.

Benjamin, W. (2009). La dialéctica en suspenso. Fragmentos sobre historia. Santiago de Chile: LOM Ediciones.

Bloom, H. (1992). La cábala y la crítica. Caracas: Monte Ávila.

Collingwood-Selby, E. (1997). Walter Benjamin: la lengua del exilio. Santiago de Chile: Universidad Arcis - LOM.

Kundera, M. (2011). La insoportable levedad del ser. Buenos Aires: Tusquets Editores.

Löwy, M. (1997). Redención y utopía. El judaísmo libertario en Europa Central: un estudio de afinidad electiva. Buenos Aires: El cielo por asalto.

Löwy, M. (2003). Walter Benjamin: Aviso de incendio. Buenos Aires: Fondo de Cultura Económica.

Scholem, G. (1983). Walter Benjamin und sein Engel. Frankfurt.: Surkhamp.

Scholem, G. (1997). Gershom Scholem: Walter Benjamin die Geschichte einer Freundschaft. Frankfurt.: Surkhamp.

\section{Palabras clave}

progreso - temporalidad - materialismo histórico - cabalismo - Walter Benjamin

\begin{abstract}
The general aim of this paper is to examine the role of Walter Benjamin's criticism of the idea of progress within his philosophy, mantaining that the roots of his political thought may be found in the kabbalistic mysticism. The main intention is to determine, following Benjamin, some of the main characteristics of the belief in progress as a problem and its relationship to a given historical normativity. This would allow to elucidate what would be the relationship that, for Benjamin, a linear and processualist understanding of history may have with a political-intellectual attitude based on conformism and indifference. Finally, this article proposes to consider the original interpretation on temporality of a Jewish mysticism trend, Isaac Luria's kabbalism, actualized in a heterodox way by Benjamin. This may let to understand in a new and particular way the temporal bond that suppose the ideas of tradition and remembrance in Benjamin's historical materalism.
\end{abstract}




\section{Facundo Bey}

\section{Keywords}

progress — temporality - historical materialism - kabbalism - Walter

Benjamin 